\title{
Toward a Common Structure in Demographic Educational Modeling and Simulation: A Complex Systems Approach
}

\author{
PORFIRIO GUEVARA \\ University of Graz (Austria)
}

\begin{abstract}
This article identifies elements and connections that seem to be relevant to explain persistent aggregate behavioral patterns in educational systems when using complex dynamical systems modeling and simulation approaches. Several studies have shown what factors are at play in educational fields, but confusion still remains about the underlying mechanisms driving observed outcomes and therefore more guidance is needed. The framework suggested here throws some ideas in that direction stressing the relevance of nonlinear complex interactions via feedbacks between education systems' transition rates - intake, repetition, dropout, and promotion - and schooling outcomes. Schooling outcomes reciprocally influence transition rates in the system generating aggregate patterns that continuously change (and are changed by) the inputs that endogenously determine them. Furthermore, this paper underscores practical and theoretical limitations of traditional quantitative models that can be addressed with a complex systems analysis and suggests future lines of investigation. Specifically, this article advocates a complexity approach ruled by the laws of thermodynamics to help detect corrupt practices in education systems and improve accountability and governance in such systems.
\end{abstract}

\section{Introduction}

Education is one of the largest contributors to individual and collective well-being and a fundamental pillar of sustainable development (World Economic Forum [WEF], 2014a). A sustained economic progress, for example, depends critically on a flow of a literate, numerate, and technically and scientifically trained workforce, which is basically supplied by the education system (Hausmann et al. 2005; Author, 2014). Sustainable development also needs to 
be inclusive and in the last few years, the ability of education to influence the social component of sustainability has taken on a great deal of importance..$^{1}$ Income inequality in developed and developing countries has been reported on the rise during last decades (Piketty, 2014; Ravallion, 2014; Sala-i-Martin, 2006) and this fact is causing concern as it is seen that uneven progress generates unrest and disconnections between most and least favored groups in society. This issue is particularly compelling for countries at initial stages of development for which primary education represents the period when human capital achieves the largest private and social returns (WEF, 2014b) and a sound educational system sets the conditions for long-term prosperity. All these reasons make a compelling case for government authorities and scholars to keep an eye on educational systems and guarantee their functioning, efficiency, and transmission of the capabilities that society demands and needs. However, there are concerns and challenges that need to be addressed to accomplish these goals.

Over the past decades, substantial advances in primary completion rates have been reported in the world as developing and emerging countries have being catching up with highincome nations. Figure 1 shows that primary completion rates for medium and low-income countries have indeed been heading in the right direction for more than two decades. On average, primary education has gained ground in almost every country, particularly middleincome ones, but for many low-income countries progress has been sluggish at best and full completion is still a distant goal. The reason for these disappointing results is that despite access to education in poor countries having improved substantially, in recent years less progress has been achieved to keep students in school until completing the whole educational process. This is the main reason why many countries that once were labeled "on track" to reach full primary completion now seem to be reaching a threshold (Bruns et al., 2003, WEF, 2014a). This is a key issue as it is increasingly understood that no country can improve and sustain its standard of living without well-functioning educational systems as their internal inefficiencies may eventually deepen inherited inequalities in society.

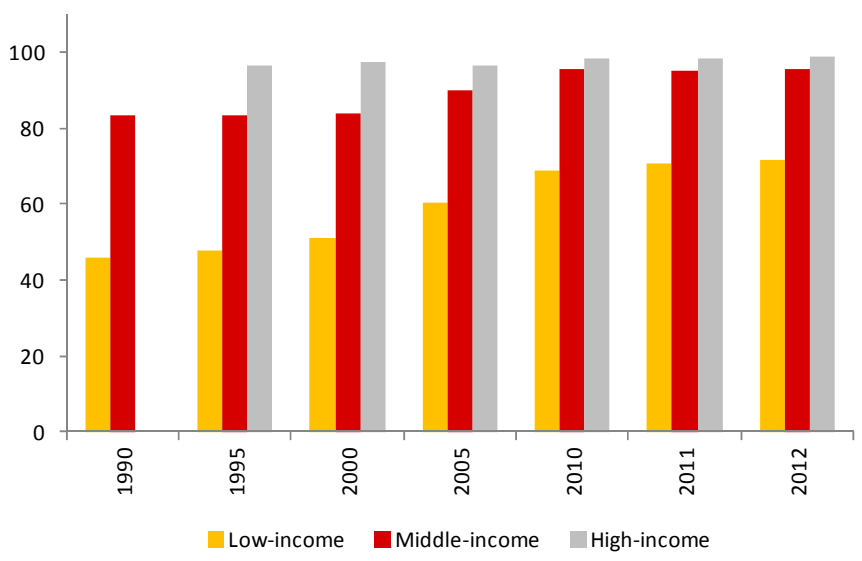

Figure 1. World Evolution of Primary Completion Rates in Education. Source: The World Bank (2014)

1 Sustainability science and sustainable development, as described by Kates et al., (2001) is “...an emerging field that seeks to understand the interactions between economic, social, and environmental processes." 
In addition, crucial challenges remain to be addressed in the near future in order to scaffold educational systems toward a position that renders education and learning meaningful for individuals and society alike. Among other themes there is a pressing need for the followings aspects (WEF, 2014a):

a) Changing demographics, in the form of aging societies or youth "gusts" - affecting countries' fiscal situations and concomitantly jobs' disponibility, emphasizing the importance of education for scientific knowledge as a means to increase opportunities for sustainable development.

b) Forward-looking perspective. Education, particularly primary school, has a relatively long payback horizon (long delays) which often clashes with policy-making cycles, of a shorter-term nature. Because a good education system requires long-term investments, keeping track of its critical inputs is often challenging.

c) Need for accountability. Given the difficulty to deny the importance of education for sustainable development, incumbents in failing educational systems may have incentives to keep them underperforming in order to swindle public resources (national or from abroad) for private illicit benefit. Detecting such practices is extremely difficult and new tools need to be developed to attack them.

One way to think all these concerns and challenges is that they are in one way or the other related to (the lack of) a systemic and dynamic understanding of the processes governing education systems and more clarity is needed in this direction. In short, several of the issues currently under discussion about sustainable development are in one way or another related to the question of whether countries in the world are advancing toward full primary completion (i.e. through age 12) at the right pace and efficiently. This article suggests avenues to advance the state of the art in modeling educational systems and proposes some research opportunities to the complexity community and enthusiasts.

\section{Making the case for a complex systems approach in demographic educational modeling}

As educational systems unfold their historical paths, they emit measurable signals suggesting that there is an underlying structure driving the observed outcomes. For example, 1) rich countries are predominantly achieving full primary completion rates while poor countries are predominantly underperforming in the same terms. 2) Almost universally, families with high educational attainment tend to have fewer children, with better educational attainment. These students tend to repeat and dropout less than those in less educated families. 3) The more educated a country is, the more productive its labor force. There are many reasons to believe that these results are directly driven by education. On one side, educated persons are more likely to have access to more and better information which then can be used more efficiently to pursue their own goals, as compared to non-educated ones. Educated households, for instance, may consider a longer time-horizon perspective when taking their consumption and investment decisions and thus tend to stick to projects with uncertain future returns and high present costs, 
like their offspring's education. More education means higher income, and both aspects are connected to better health which in turn allows a worker to be more productive.

The influence that individual factors have on educational systems has been traditionally quantified by econometric studies (Coleman et al., 1966; Hanushek, 2002; Meghir \& Rivkin, 2010). In general these studies address the issue using education outcomes data and relating them to a number of factors, e.g. assessing the impact of class size on test scores and the consequences of policy changes (Kremer, Brannen, \& Glennerster, 2013). However, more recently, Koopmans (2014a, 2014b) and Stamovlasis and Koopmans (2014) have questioned single outcome measurements research in education arguing that in an increasingly interconnected world multiple factors compound each other's effects in ways that both increase and diminish their aggregate influence. These authors consider that traditional approaches overemphasize the linearity of their causal effects. They advocate for a more systemic-oriented research that captures the learning process as it occurs in reality. This is, in some extent, conceded by Deaton (2010) and Hanushek and Woessmann (2014) who are aware of the methodological challenges that estimating econometrically the education production function has at aggregate level due to the lack of exogeneity of inputs (in a statistical sense) and reverse causation. As Hanushek and Woessmann (2014) put it succinctly,

Given this substantial scope for endogeneity bias, least-squares estimates of the (education production) equation need to be interpreted with great care, even when they control for a large set of observable input factors. (p.149)

With no denial of the intellectual contribution that statistical and econometric methods have provided to educational research, this article moves beyond not only from the discussion on which factors are the most relevant in driving observed results; it is also necessary to provide space for dynamic and complex methods to address educational issues from an integrated perspective and bring about fresh questions and hypothesis about how such systems work in reality. An approach ruled by complex interactions will deepen our understanding of educational systems and such an approach can be extended for the purpose of designing and evaluating feasible, cost-effective policies to improve system performance.

\section{Is a complex dynamical system modeling the right approach needed?}

There are several issues related to approaching education as a nonlinear and dynamic system. One issue is associated to the definition of a complex system and its main features and properties. Additionally, there are so many aspects of education that can be approached using a complex framework that it is necessary to specify what kind of problems or aspects make sense to tackle under this approach and why.

There is no single commonly-accepted definition of complexity. When incumbents attempt to address the challenge, they may end up defining a concept that is specific to the context or particular area of interest (Haglund, Jeppsson, Strömdahl, 2010). This lack of precision, however, in no way reduces the respectability of the discipline (i.e., despite the fact that there is no universally agreed definition of life, biologists and psychologists are well-respected scientists) but lacking such universally accepted definition compels those in the field to try the second best alternative, describing complexity in term of its features and properties. A complex 
system thus is said to have as a minimum the following characteristics (Durlauf, 1998; Mitchell, 2009, Sterman, 2000).

- Simple components - relative to the whole system.

- Feedbacks - closed chains of interactions between the elements of a system and the whole.

- Nonlinear interactions among components, roughly meaning that the whole is more than the sum of the parts.

- Emergent behavior, which relates to unpredictable, non-deductible and irreducible patterns that arise when all these properties come together in a system.

When all these properties are merged in a simulation model, such systems are also expected to display features like tipping points, phase transitions, and resilience, among other properties. These terms and properties are more commonly utilized in physics than in educational fields, but as scientific disciplines are increasingly mingled in modern scientific work, a common language will certainly facilitate the communication between different disciplines and presumably increase their contribution to society.

Educational systems are indeed highly complex and dynamic ecosystems (Mason, 2009;

Reilly, 2000; Stamovlasis \& Koopmans 2014); they encompass a very large number of individuals, elements and factors interacting via feedbacks in a nonlinear fashion. As these elements change and interact with the collective patterns they jointly create over time, understanding educational processes requires a systemic perspective.

\section{Dynamic Hypothesis: Feedbacks and nonlinear interactions}

Interactions among the elements of systems are crucial to unlock the emergent property of complex structures, which in words describe situation in which the whole is larger than the sum of its parts. These interactions can be illustrated by causal loop diagrams which show such connections within a dynamical system. They describe nonlinear closed-chain interactions within the system and they come in two different fashions: positive and negative feedbacks. In a positive feedback, a change between two linked variables produces a response in the same direction: more (less) of one variable leads to more (less) of the other variables, while in the negative case the response is in the opposite direction. One particularity of education, especially primary education, is the dominance of positive feedbacks ${ }^{2}$ or increasing returns, a characteristic prevalent in information goods. ${ }^{3}$ From the supply side for example, once society creates the conditions to provide educational services, the marginal cost of teaching an additional pupil is insignificant compared to the cost already incurred. This means that an additional student in a classroom can receive approximately the same opportunities for learning as her classmates at a near-to-zero additional cost (unless classroom congestion is reached).

${ }^{2}$ Increasing returns mean that doubling all inputs in a production function lead to a more than double effect in the expected output.

${ }^{3}$ Information goods are objects that are both non-excludable and non-rivalrous in that individuals cannot be effectively excluded from use and where use by one individual does not reduce availability to others. 
In addition, increasing returns may also be relevant in the demand of education through network effects, supported by an already established base of educated people. ${ }^{4} \mathrm{~A}$ direct consequence of network effects is the tendency of things to gain more advantage when they go ahead, or to fall further behind when they go behind. Increasing returns are then a kind of positive feedback (see Arrow, 2000) and the evidence suggests that they are endemic in businesses, markets, and society in general, favoring successful ones and penalizing those who fail. The presence of increasing returns then generates disequilibrium instead of equilibrium in a system embedding them. Two key positive feedbacks are described next. The first describes an intergenerational effect of literate adults influencing youngsters' school decisions (Durlauf, 1998); and the second represents educated population influencing aggregate economic growth (Lucas, 1988; Dowrick, 2003).

Feedback from literate population to school-aged children

Instead of deciding in isolation, people are members of a community that form a complex network of social, economic, and cultural interrelations. ${ }^{5}$ With respect to education decisions, one may assume persons derive a benefit in function of the number of educated individuals (human capital) with whom they socially interact. Socio-economic relations are then endogenously created by the interaction of individuals. A dynamic extension of this view allows conjecturing that those decisions taken by members of one generation influence choices made by members of the next generations. ${ }^{6}$ Note that a fundamental aspect in the model definition is the existence of a feedback from the aggregate characteristics of the environment in which individuals are embedded that influence their decisions. Once these individual decisions are aggregated, they feedback into the macro-characteristics of the environment and the individuals' courses of action. In particular, this paper focuses on the dynamic impact of a population responding to some specific characteristics of the population itself (e.g. the percentage of educated people in the total). Of interest are the behavioral patterns generated by systems governed by feedbacks that tend to perpetuate initial conditions, i.e., educational systems unintentionally reinforcing poor outcomes due to disadvantaged initial conditions. If the education system performs badly; it has consequences beyond the direct cost that illiteracy has on each individual and is cumulative in time. For example, a low share of educated adults exerts low pressure on the current school-age cohort to support its formal education by, for example, underestimating the importance of education, curtailing support of school-related activities that increase repetition and desertion, etc. ${ }^{7}$ More repeaters and deserters increase illiteracy in the population, thereby worsening the situation.

The same argument holds the other way around; a highly educated population will motivate children to get enrolled and stay in school with good accomplishment (Oreopoulos,

\footnotetext{
${ }^{4}$ In economics and business, network effects refer to the value of a product or service that an individual perceive depending on the number of others using it.

${ }^{5}$ Commons (1950) says: "collective action is the general and dominating fact of social life. Humans are born into a process of collective action and become individualized by collective action".

${ }^{6}$ In the economic literature they are denominated "role models". See Bénabou (1993), Durlauf (1996).

7 This argument suggests that the probability of repetition and drop out is inversely proportional to the literate population in determined society or region.
} 
Page, \& Stevens, 2003). In this case, the effect strikes directly the system's transition rates (R1 and $R 2$ in figure 2). A high ratio of literate persons reduces repetition rates because parents persuade and are persuaded by other parents to support children's schooling activities and their collective efforts are more effective (Durlauf, 1998). This leads to an improvement in promotion rates leveraging primary graduates which also increases the amount of literates in the population.

\section{Positive feedback from literate population to economic growth}

Economic growth determines how much improvement will occur in the overall living standard of a society in time. The aggregate relationship between the quality of labor force (human capital) and economic growth is perhaps even more important than the impact of an individual's

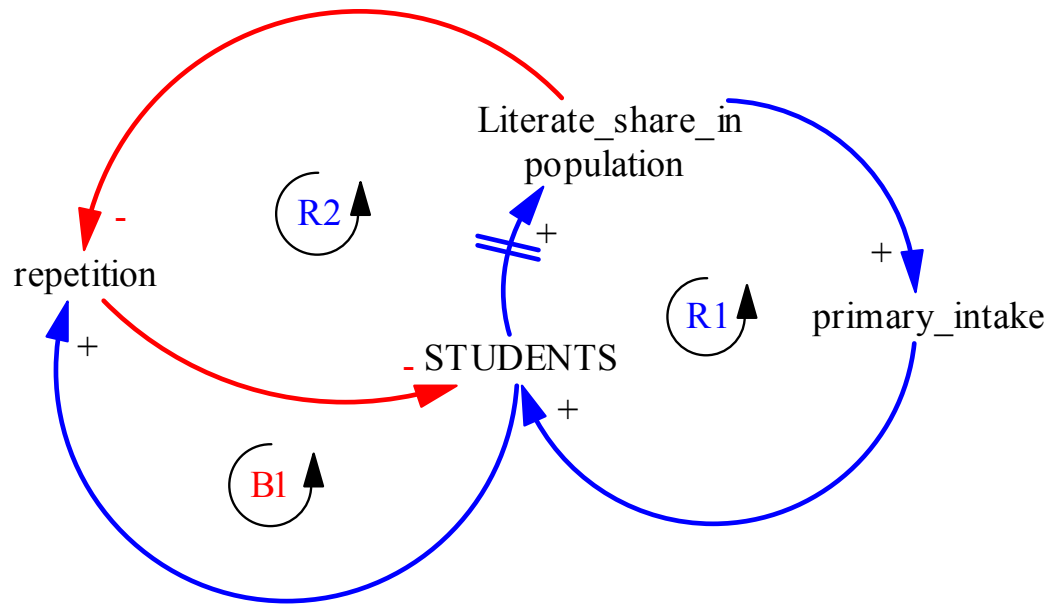

Figure 2. Positive feedbacks from adults to school-age population

human capital on individual productivity and incomes. It was after Lucas (1988) and Romer (1990) that the idea to relate education and economic growth was theoretically encouraged in the literature. The idea behind such causal links is a crucial aspect of education and learning, they produce ideas and information, which are non-rival goods. Non rivalry roughly means that the use of an object (information in this case) by one party does not preclude, reduce or make more costly the use by another. While individuals invest in education throughout their lives, as the accumulated human capital is attached to every individual it needs to be replaced with every generation. This is not an issue for productive ideas, which once properly gathered and transmitted, do not pass away with the person who generated or adopted them. These productive ideas are responsible for the long-term economic growth of countries (Romer, 1990). In other words, though human capital is subject to diminishing returns (a negative or balancing feedback), a side effect - knowledge transmission and accumulation - is not. Education thus allows an adequate diffusion of ideas (and therefore productivity) throughout population. That is why the potential of education to influence long-run economic growth is considerable. ${ }^{8}$ An

${ }^{8}$ This means that its effect occurs in the growth rate rather than in the income level. See Dowrick (2003). 
implication of this argument suggests that low and unequal schooling limits the transmission of ideas and economic progress among individuals and societies.

Economic progress encourages education as well (Hanushek \& Kimko, 2000). It is generally accepted that education is good and that is the main reason parents normally enroll their children in school. A country with healthy economic growth is likely to impact positively the household budget which thus helps to finance children's education. In words, R3 (figure 3) shows the positive effect from per-capita human capital on the economic growth rate in the country, which also affects positively the per-capita income creating opportunities to finance the education of young-cohorts. Better incomes increases households' affordability of the direct and indirect costs of education. Then a larger amount of pupils can be enrolled in school (R4) and more students will finish primary school than otherwise would be (because there will be less dropout and the share of persons with a complete primary education in the country increases (after some time passes).

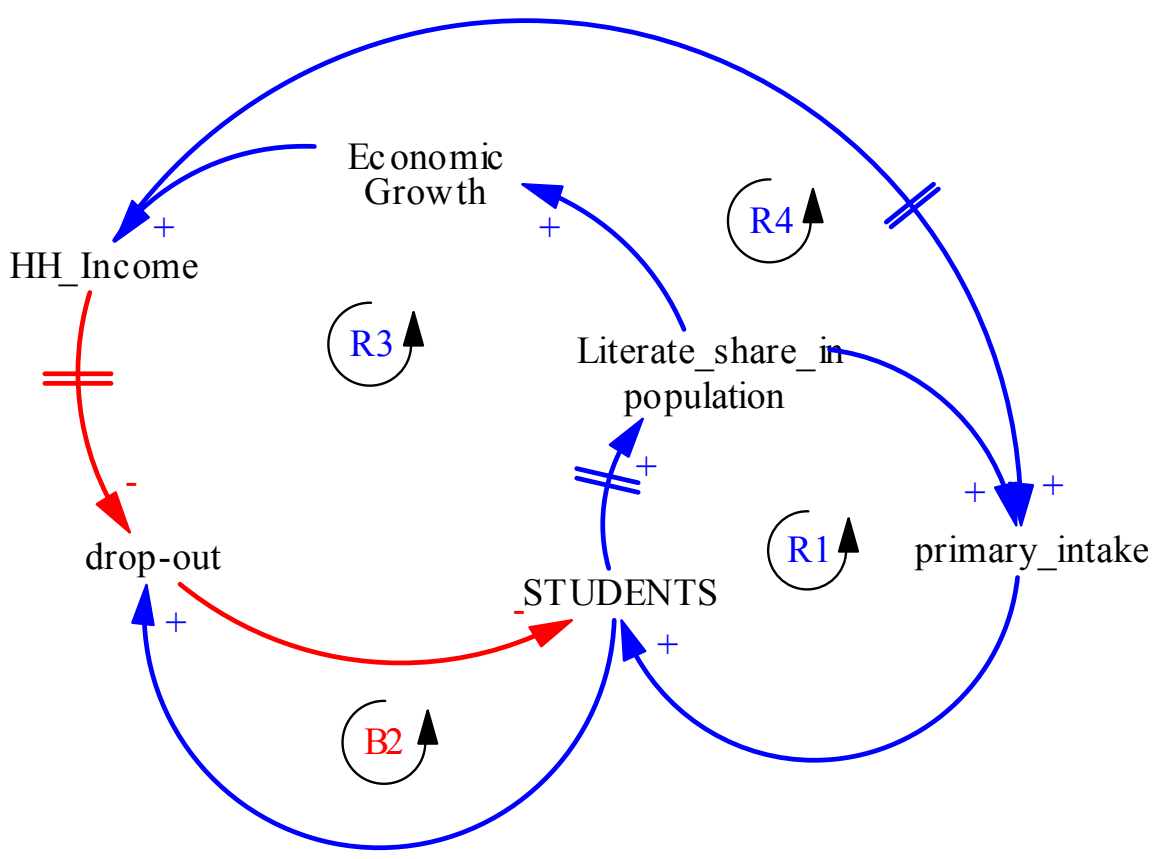

Figure 3. Positive feedbacks from literate population to economic growth

The two positive feedbacks just described meet the conditions to induce an unstable equilibrium in the underlying system, which then open the window for a path-dependent-like system that displays a sort of self-perpetuating behavior. Such systems present traits associated with winner-take-all, lock in, etc. situations, which could potentially shed light on the current debate on the intergenerational transmission of inequalities in society or development traps that compel education systems to fall short of reaching a maximum achievement.

\section{Are complex system modeling and simulation any good?}

As we know, there are known knowns, there are things we know we know. We also know there are known unknowns, that is to say we know there are some things we do not know. But there are also unknown unknowns -the ones we don't know we don't know. And if one looks 
throughout the history of our country and other free countries, it is the latter category that tend to be difficult ones. (DoD news Briedfing - Secretary Rumsfeld and Gen.Myers, 2002). ${ }^{9}$

Picking up on economist Frank H. Knight's ideas, the former US Defense Secretary Donald Rumsfeld put the unknowns out in the context of uncertainty and complex management. ${ }^{10}$ Table 1 arranges these categories in four quadrants: known-knowns (KK), known-unknowns (KU), unknown-knowns (UK) and unknown-unknowns $(U U)$. For the purpose of this article it is useful to propose a taxonomy which depends on the timeline of events' occurrence. Under this perspective then, the first two categories encompass past events, so either we know these events happened in the past and the difference between both categories lies in whether we have enough information to measure their impacts and/or the variables influencing these events, so it is possible to predict with reasonable accuracy what are the possible effects in case the same conditions apply in the future. Econometric analysis, randomized experiments and other statistical methods can be used for that purpose. In the first case one may have enough data that provides reasonable evidence of the causal relationships and the value of the estimated coefficients is consistent with what theoretical models predict. Thus, the first category, knownknowns are these events that have been correctly identified and the impact of the relevant variables is properly measured. The second category, known unknowns are those past events which in despite of being aware of their existence have not been accurately measured. One may even have historical data, but a quantification of the relevant coefficients is inconclusive or it is not possible to assign the respective contribution to multiple elements. An example of this category is the Robert Solow's total factor productivity (the well-known Solow's residual in economic growth theory) that he labeled as a measure of our ignorance. It is that part of productivity for which researchers are still not able to find measurable inputs.

The other two categories are the unknowns, and they refer to future events. So, by definition, none can predict when (or whether) they will ever happen. The difference between both of them is that in the unknown-knowns managers are somehow aware of the possibility that determined event will happen, but they do not know the probability distribution or when it will happen (e.g. what is the probability that an earthquake will strike a particular seismic area in one month?, or will depletion of the world oil reserves occur within 20 years?). Finally, the last categories, unknown-unknowns, are future events that people still are not aware of their existence because there is no previous information about them. Thus, how it is possible to identify things that one does not know that one does not know?

Events in quadrants $K K, U K$, and $K U$ can be approached by historical research as a mean to reduce the magnitude of our collective ignorance. In practical terms, for contingencies in any of these quadrants people tend to select the option that led to the best average payoff in the past. The UU quadrant, however, is a bit more complicated. Most decision-makers ignore the $U U$ either because such events are so rare that people tend to underweight their relevance or because stakeholders are not even aware of their existence. Most people focus on things they know and things that they know that they do not know, and certainly, rare unknown events

\footnotetext{
${ }^{9} \mathrm{http}: / /$ www.defense.gov/transcripts/transcript.aspx?transcriptid=2636

10 See Dombret (2012). Beware Unknown-unknowns. International Economy, Spring. Retrieved from http://www.international-economy.com/TIE_Sp12_Dombret.pdf.
} 


\begin{tabular}{|l|l|l|}
\hline $\begin{array}{l}\text { Known } \\
\text { (past) }\end{array}$ & $\begin{array}{l}\text { Known } \\
\text { whose occurrence is known and } \\
\text { there is enough information and } \\
\text { conclusive evidence. }\end{array}$ & $\begin{array}{l}\text { Unknown } \\
\text { whose occurrence is known, there is } \\
\text { uncertainty because of imperfect or } \\
\text { incomplete information. Evidence is } \\
\text { still inconclusive. }\end{array}$ \\
\hline $\begin{array}{l}\text { Unknown } \\
\text { (future) }\end{array}$ & $\begin{array}{l}U K-\text { Unknown-knowns. Future } \\
\text { events whose occurrence is } \\
\text { unpredictable despite people being } \\
\text { aware of their existence. }\end{array}$ & $\begin{array}{l}U U \text {-Unknown-unknowns. Future } \\
\text { events that people are not aware of } \\
\text { their existence. }\end{array}$ \\
\hline
\end{tabular}

Table 1. Connecting past, present, and future through modeling and simulation

are normally ignored because of its unchartered territory nature and the tools to navigate such territories are scarce or inexistent.

One of the challenges to good policymaking has to do with the fact that it requires the ability to connect past, present and future (Alhadeff-Jones, 2009). Therefore, to effectively advance education in society decision makers needs to learn how to fill out the quadrants with valuable information. Complex system modeling is an appropriate tool for analyzing the all four quadrants through policy simulation for the following reasons: 1) One can approximate the "size" of the UU quadrant (e.g. via extreme-case scenarios); 2) educational managers may attempt to "reduce" the size of the $U U$ quadrant by filling in the UK quadrant; 3) through modeling and simulation managers learn to identify not only what is relevant to know, but also what is unknown, particularly exploiting the emergent property of a complex system. Given the nonlinear nature of complex models, key insights can be gained by simulating the impact of simultaneous policy measures since usually their total effect in the system is not the sum of the individual impacts (Guevara \& Posch, 2014).

Simulation models can be calibrated to mimic real situations. But complexity models are also effective to deconstruct the rules that have been used in past events (the knowns). Therefore, when such models and rules conform to solid scientific principles they can increase the reliability of predictions, as the next subsection points out.

\section{Consistency in modeling and simulation: A contribution from the Laws of Thermodynamics}

Although adapting the laws of thermodynamics in demographic educational modeling sounds a bit abstract in the educational context, the rationale to include such laws is to formalize and make explicit the occurrence of the educational process at aggregate levels and to visualize its macroscopic properties under particular conditions. Complying with these laws in modeling educational systems allow researchers to build an analogy with other physical phenomena of the real world and capture the dynamical processes hypothesized in the literature such as steady-state equilibrium, phase transitions, etc.

A salient aspect of a complex system model rests in the possibility of complying with the first and second laws of thermodynamics. The first law of thermodynamics (conservation of the matter) states that the total energy of an isolated system can be transformed from one form to another, but cannot be created or destroyed (Carroll, 2010). The first law is respected in the 
modeling procedure if, for example, the number of students flowing into the system matches up the number of students who ever go out to rule out the possibility that the model creates people artificially due to an error in the computer code.

The second law of thermodynamics predicts that the entropy of an isolated system either remains constant or increases with time (Carroll, 2010), which then provides a sense of the direction of time and therefore the causality of the education process. The definition of the second law is a bit controversial in the sense that the concept of entropy comes in different flavors (Brodu, 2009 presents a comprehensive revision of the concept of entropy from the perspective of complexity). ${ }^{11}$ Guevara and Posch (2014) consider that a definition of entropy that is close to the thermodynamic sense is more useful for purpose of rigorous complexity modeling, as students in educational systems can be considered like the energy of the system. As energy flows throughout the different stages of the system (in compliance with the first law of thermodynamics) some energy gets lost. So, under this perspective, the entropy of a system can be computed by explicitly measuring such losses during the process, which once applied to an educational context, refers to the only two possibilities to withdraw students from the system: via dropout or final graduation.

Entropy, in an educational simulation model, thus can be tracked by two mechanisms. First, students flow through the educational structure from non-educated to educated population (the arrow of time points in one single direction). This idea explains how the education process occurs in real life, that is, in which direction. For instance, one can observe people going to school from the first grade and progressing until finishing primary school. The time arrow thus only goes in one direction and that process is irreversible (one will unlikely observe a person moving from sixth grade to fifth grade, ..., first grade). In other systems, such process is not irreversible as people do not necessarily flow in one single direction (e.g. transportation system). Second, the primary completion rate (PCR), a flow measure of the number of graduates from primary school compared to the size of a specific age cohort, is used here to measure entropy in educational systems as this indicator also accounts for the dropouts. Thus, there is a tendency for the primary completion rate to reach a maximum level when there is full intake (all school-age children are enrolled in school) and there is no dropout and no repetition. As dropout and repetition rates are a sort of energy dissipation in this system, thus maximum entropy will be reached when such flows are minimized and promotion is maximized.

Both laws of thermodynamics are essential to increase the reliability of model equations when they are used for predictions. The reason is straightforward, if we ask to a scientist to point out what principles of physics will remain valid over the coming centuries; the second law is $\mathrm{j}$ one such principle (Carroll, 2010 p.32). Therefore one can be confident that a model

\footnotetext{
${ }^{11}$ There are numerous ways to approach the concept of entropy e.g. thermodynamic, statistical, information, etc. The thermodynamic version of entropy measures the amount of heat loss when energy is transformed to work. Another definition, a la Boltzmann, adopts a statistical sense in which the macrostate of a system corresponds to the maximum possible alternatives that a finite number of microstates can be arranged in a particular way (Haglund et al. 2010; Carroll, 2010). Finally, the term entropy was introduced in information theory by Shannon (1948) as a measure of the information produced in the stochastic process of forming a message.
} 
rooted in these laws will remain valid in the future. Other research methods are not as suitable to comply with these laws, which then reduce the confidence one may have when constructing consistent future predictions (Guevara et al., 2014). This is a key issue for researchers and decision makers when predicting the behavior of educational systems in the future. Changes in intake, repetition, and drop-out rates, or simple adjustments in the age students start school could render widely-used linear extrapolation techniques misleading to predict how educational systems will evolve as well as the impact of educational reforms. This is so because simple trend projection methods cannot grasp the complex interactions that play out within these systems over time and therefore they cannot display properties such as steady-states and phase transitions that are pervasive in these contexts.

\section{An application: detecting ghost students}

Akerloff and Shiller (2009) state:

Corruption scandals are always tremendously complicated. Yet they are also tremendously simple. They are simple because they always involve the violation of elementary principles of accounting regarding how much money can legitimately be taken. They are complicated precisely because the participants seek to shroud in complexity the violation of these simple principles.

Spotting ghost students (faked enrollment in educational systems) in official statistics is almost impossible as they are nearly invisible to traditional radars, i.e., they easily disappear when school auditing starts. That makes them notoriously difficult of computation in practice and progress on measuring the extent of such activities has been limited to surveys or experts' assessments of doubtful validity (UNODC, 2010). Nonetheless, in some particular cases researchers may have the opportunity to uncover such illicit activities if, as pointed out by Akerloff and Shiller, they are able to find the principle that corruption activities violate and use that to underscore the underlying inconsistency. For the detection of ghost students in education the First Law of Thermodynamics (conservation of matter) is just that principle (Guevara, 2013). So, if in a dynamic complex model, the number of students flowing into the education system equals those who ever flow out assures that people are not created artificially (as ghost students are), then any systematic discrepancy between observed and simulated data should arise from the manipulation of education data and not from programming bugs in the model.

The potential to detect ghost students is a key finding in theoretical and practical terms. The general character of the underlying principle of conservation of matter that is violated by the presence of these students and potentially captured in a simulation model is reason for optimism, as it occurs largely independently of the precise mechanism involved in committing the hoax and how nimble are fraudsters in mutating their strategies. What this argument suggests is that once similar principles are duly incorporated in the modeling practice, complex systems analysis can improve substantially our ability to understand corruption and its dynamics by building a sound framework for the measurement of illicit practices in certain systems which then might play a determinant role when it comes to policy making, a field that has shown only modest progress in the last decades. This lack of progress in detecting 
corruption activities in education is costing enormous amounts of resources in countries like Nicaragua, Colombia, and Pakistan, among many others.

\section{Summary}

Complex dynamic mechanisms drive many social, economic, and natural processes in modern highly-connected societies and the prospects for advancing at the right pace in human sustainability can more likely be accomplished if the impact of past, present, and future events that shape the development paths of countries are identified and understood. But satisfactory answers need consistent models showing alternative paths and the consequences that intertwined factors in human and natural systems may have on the shape and direction of such paths. Complexity modeling and simulation can be regarded as an informed guide for decisionmaking intelligence providing consistent forecasts when properly designed and constructed. Decision-making intelligence that is timely, relevant, and accurate adds significant value to decision makers when such insights provide consistent information that reduces the "unknowns" of future or past events; this is what a well-designed model should do. Note that this argument does not suggest that model forecasts should be exact predictions of future events. What it indeed suggests is that in principle all simulated paths should be consistent predictions based on the logic of the model's structure and the impact of the assumed nonlinear relationships. So, if the model's logic has been articulated in a consistent way, the model predictions will remain sound, regardless of which particular scenario unfolds, and that provides sound information about the real system. This perspective is likely to lead to a view that as we learn more about the functioning of complex systems, in general, decision makers will interfere more efficiently in the real-world.

As this article has discussed, a very useful perspective in demographic education modeling might consider populations as a collection of elements whose combined activities shape the realm of the environment they are embedded in -the behavior of individual components influences the dynamic behavior observed at aggregate level- and the aggregate behavior of that population reciprocally influences individuals' courses of action. Of particular interest is tracking behavioral patterns generated by educational systems governed by feedbacks that tend to perpetuate initial conditions, i.e., educational systems striving to reinforce poor outcomes due to disadvantaged initial conditions.

This paper has also suggested that certain illegal activities may be detected and probably better understood with complexity system modeling and simulation once a researcher builds enough confidence in model results to notice that a persistent deviation between observed and simulated can be rule out as false positives due to an error in the model specification or coding. A dynamical complex systems model thus could be used as an early warning tool to alert for the presence and magnitude of ghost students in a system.

Finally, a simulation model should track the skills earned by students at different stages of the educational course (e.g., using data from standardized tests or other methods that capture learning at schools) and not just the number of students. Several reasons may justify this. While the quantity of schooling has expanded considerably in developing countries, quality is often disappointing (in term of what students effectively learn). Developed countries present better 
outcomes in education in large part thanks to the increase in the quality -and not necessarily to the quantity of their educational resources. One likely implication of these results is that the process of coming up with versions of educational resources could have a decisive impact on the human capital accumulation process itself, thus with an impact on the system performance. Given its relevance for sustainable development, it seems necessary to better understand the process of quality formation and transfer in primary school as it is the basis of the whole process of human capital formation in countries.

\section{References}

Akerlof, G. and Shiller, R. (2009). Animal spirits: how human psychology drives the economy, and why it matters for global capitalism. Princeton University Press.

Alhadeff-Jones, M. (2009). Transformative learning, sustainability and the issue of time. In M. Alhadeff-Jones (Chair), International Perspectives on Transformative Learning and Sustainability. Panel conducted at the 8th, Transformative Learning Conference, Bermuda.

Arrow, K. J. (2000). Increasing returns: historiographic issues and path dependence. European Journal on History of Economic Thought 7(2) 171-180.

Autor, D. (2014). Skills, education, and the rise of earnings inequality among the "other 99 percent". Science 344, pp.843-850.

Brodu, N. (2009). A synthesis and a practical approach to complex systems. Complexity 15 (1), 36-60.

Bruns, B.; Mingat, A., \& Ramahatra, R. (2003). Achieving universal primary education by 2015 a chance for every child. Washington, D.C.: The World Bank.

Carroll, S. (2010). From eternity to here: the quest for the ultimate theory of time. Penguin Group.

Coleman, J.S., E.Q. Campbell, C.J. Hobson, J. McPartland, A.M. Mood, F.D. Weinfeld, \& R.L. York. (1966). Equality of educational opportunity. Washington, D.C.: U.S. Government Printing Office.

Commons, J. R. The economics of collective action. Madison: The University of Wisconsin Press, 1950.

Dowrick, S. (2004). Ideas and education: level or growth effects and their implications for Australia. In: Growth and Productivity in East Asia. NBER-East Asia Seminar on Economics, (pp. 9-40). National Bureau of Economic Research, Inc.

Durlauf, S. N. (1998). What should policymakers know about economic complexity? Washington Quarterly. 21 (1), 157-165.

Guevara, P., Lopez, L., Posch, A., Zuniga, R. (2014). A dynamic nonlinear model for educational systems: a simulation study for primary education. Nonlinear Dynamics, Psychology, and Life-Sciences Vol. 18 (1).

Guevara, P., Posch, A. (2014). Dynamic complexity, entropy, and coordination in educational systems: A simulation of strategic and exogenous interventions. Systemic Practice and Action Research. Published online. DOI 10.1007/s11213-014-9327-y.

Guevara, P. (2013). Nonlinear dynamics of ghost busters: detecting fraud with system dynamics. Proceedings of the 31st International Conference of the System Dynamics Society, Cambrigde, MA, USA.

Haglund, J, Jeppsson, F., Strömdahl, H. (2010). Different senses of entropy-implications for education. Entropy $12,490-515$.

Hanushek, E. A. (2002). Publicly provided education. In: A. J. Auerbach \& M. Feldstein (ed.), Handbook of Public Economics (pp. 2045-2141). Amsterdam: Elsevier.

Hanushek, E. A., Kimko, D. (2000). Schooling, labor force quality, and the growth of nations. American Economic Review, 90 (5), 1184-1208.;

Hanushek, E., and Woessmann, L. (2014). Institutional structures of the education system and student achieve1nent: a review of cross-country economic research. In Strietholt et al . eds. Educational Policy Evaluation through International Comparative Assessments Waxman 2014. Retrieved on August 2014 from http://hanushek.stanford.edu/sites/default/files/publications/Hanushek\%2BWoessmann\%202014\%20EduP olEval.pdf. 
Hausmann, R., Rodrik, D., Velasco, A. (2005). Growth diagnostics. Retrieved from http://www.hks.harvard.edu/fs/drodrik/Research\%20papers/barcelonafinalmarch2005.pdf (August, 2014).

Deaton, A. (2010). Instruments, randomization, and learning about development. Journal of Economic Literature, vol. 48, pp. 424-455.

Kates, R.; Clark, W.; Corell, R.; Hall, J.; Jaeger, C.; et al. (2001). Sustainability science. Science (Science) 292 (5517): 641-642.

Koopmans, M. (2014a). Nonlinear change and the black box problem in educational research. Nonlinear Dynamics, Psychology, and Life Sciences, Vol. 18, (1) pp. 5-22.

Koopmans, M. (2014b). Change, self-organization and the search for causality in educational research and practice .Complicity: An International Journal of Complexity and Education 11(1).

Kremer, M., Brannen, C., \& Glennerster, R. (2013). The challenge of education and learning in the developing world. Science 340, 6130, pp. 297-300.

Lucas, R.. E., Jr. On the mechanics of economic development. Journal of Monetary Economics 22 (1988).

Mason, M. (2009). Making educational development and change sustainable: insights from complexity theory. International Journal of Educational Development 29, 117-124.

Meghir, C., \& Rivkin, S.G. (2010). Econometric methods for research in education. NBER Working Paper 16003, Cambridge, MA.

Mitchell, M. (2009). Complexity: a guided tour. Oxford University Press.

Oreopoulos, P., Page, M. E., \& Stevens, A.H. (2006). The intergenerational effects of compulsory schooling. Journal of Labor Economics, 24(4), 729-760.

Piketty, T. (2014). Capital in the 21 st century, Harvard University Press.

Ravallion, M. (2014). Income inequality in the developing world. Science 344, pp. 851-855.

Reilly, D. (2000). Linear or nonlinear? A metacognitive analysis of educational assumptions and reform efforts. International Journal of Educational Management. 14 (1), 7-15.

Romer, P. (1990). Endogenous Technological Change. Journal of Political Economy, 98, 5, p. 2.

Sala-i-Martin, X. (2006) The World Distribution of Income: Estimated from Individual Country Distributions. Quarterly Journal of Economics. May 121 (2).

Stamovlasis, D., \& Koopmans, M. (2014) Education is a dynamical system. Nonlinear Dynamics, Psychology, and Life Sciences, 18(1), 1-4.

Sterman, J.D. (2000). Business dynamics. McGraw-Hill.

UNODC. (2010) Methodologies, including evidence-based approaches for assessing areas of special vulnerability to corruption in the public and private sectors. United Nations CAC/COSP/WG.4/2010/4. Retrieved on August, 2014 from http://www.unodc.org/documents/data-and-analysis/statistics/corruption/WG4 doc-4FINAL.pdf.

World Economic Forum. (2014a). Education and Skills 2.0: New Targets and Innovative Approaches. Klaus Schwab editor. $\quad$ Retrieved from http://www3.weforum.org/docs/GAC/2014/WEF GAC EducationSkills TargetsInnovativeApproaches Bo ok 2014.pdf.

World Economic Forum. (2014b). The Global Competitiveness Report 2013-2014. Klaus Schwab editor. Retrieved from http://www3.weforum.org/docs/WEF GlobalCompetitivenessReport 2013-14.pdf.

World Bank. (2014). World development indicators 2014. The World Bank, Washington D. C. Retrieved August, 2014 from http://data.worldbank.org/data-catalog on.

\section{About the Author}

Porfirio Guevara is Assistant Professor at University of Graz, Austria. He holds a Ph.D. in Sustainability Management, University of Graz, Austria; M.Ph. in System Dynamics from the University of Bergen, Norway; MSc. in Economics from the University Pompeu Fabra, Barcelona (Spain); and B.Ph. in Economics, University of Costa Rica. His research interests include complex system dynamics modeling and simulation and economics of technological change and education. Correspondence: porfirio.guevara-chaves@uni-graz.at 
(C) Copyright 2014. The author, PORFIRIO GUEVARA, assigns to the University of Alberta and other educational and non-profit institutions a non-exclusive license to use this document for personal use and in courses of instruction provided that the article is used in full and this copyright statement is reproduced. The authors also grant a non-exclusive license to the University of Alberta to publish this document in full on the World Wide Web, and for the document to be published on mirrors on the World Wide Web. Any other usage is prohibited without the express permission of the authors. 